\title{
In Silico Investigation on the Beneficial Effects of Medicinal Plants on Diabetes and Obesity: Molecular Docking, Molecular Dynamic Simulations, and ADMET Studies
}

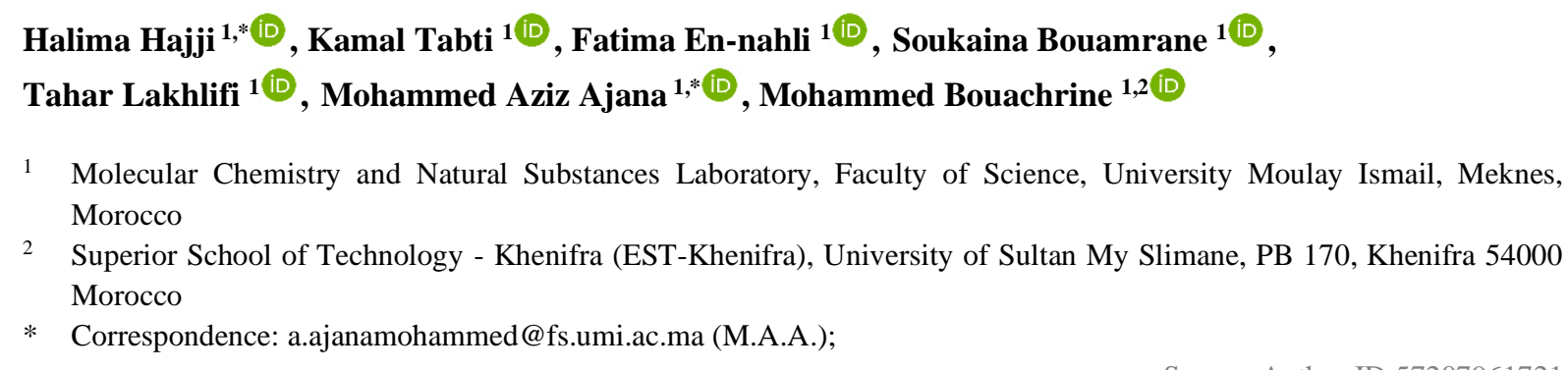

Received: 9.09.2021; Revised: 14.10.2021; Accepted: 18.10.2021; Published: 20.11 2021

\begin{abstract}
Currently, obesity leads to health problems, including type 2 diabetes. These two diseases are closely linked. Despite the spectacular development of the synthesis of active ingredients and chemotherapy, we have not ceased to be interested in medicinal and aromatic plants, their effects, indications, and methods of use. Thus, we see that the number of herbal medicine or plant substances is growing in a very important way. The present study was carried out on the chemical structures of 16 plants, whose existence could help reduce obesity and its complications. Through molecular docking methods, ADMET, and molecular dynamics. Due to the interaction, and good stability, we have found that quercetin may have the obesity treatment.
\end{abstract}

Keywords: obesity; diabetes; medicinal plants; Molecular Docking; ADMET; Molecular Dynamics.

(C) 2021 by the authors. This article is an open-access article distributed under the terms and conditions of the Creative Commons Attribution (CC BY) license (https://creativecommons.org/licenses/by/4.0/).

\section{Introduction}

Diabetes and obesity are two major epidemics operating around the world [1]. The observation is simple: there are 400 million obese adults on Earth, and they will be more than 700 million in 2025 [2,3]. Obesity is defined according to the World Health Organization (WHO) as an excessive or abnormal accumulation of fat in the body, which may affect general health. It is a complex, chronic disease with potentially serious complications. Obesity is internal suffering. It is measured by the body mass index (BMI), calculated by dividing the body weight (in $\mathrm{kg}$ ) by the square of its size $\left(\mathrm{m}^{2}\right)$; a person with a $\mathrm{BMI} \geq 25 \mathrm{~kg} / \mathrm{m}^{2}$ is considered overweight. As soon as BMI exceeds $30 \mathrm{~kg} / \mathrm{m}^{2}$ an individual is considered obese $[4,5]$. The higher the BMI, the elevated risk of comorbidities (secondary illnesses) and premature death [6,7]. The case of obesity is particularly visible since it is indeed something that can be seen. Among the main networks that promote weight: an imbalance due to a change in eating habits, decreased physical activity, smoking cessation [8], alcohol consumption [9], certain drugs, professional or personal family difficulties, periods of psychological or social vulnerability [10]. Obesity can lead to serious health problems: heart disease, breathing disorders (sleep apnea or some lung disease asthma), type diabetes II, musculoskeletal disorder 
cancer each year at least 2.6 million people die from overweight or obesity, which is the 5th leading cause of death in the world [11-13].

Recently, research shows that an obese person is 3 times more likely to have diabetes than a non-obese person. Biologically speaking, the more overweight, the greater the amount of fat in your body, the more insulin your body needs, which is one of the important links between obesity and diabetes [14]. At the same time, there is an increase in blood sugar. Indeed, fat will provide energy to the muscle at the expense of glucose, leading to a rise in blood sugar. The pancreas will secrete too much insulin to try to reduce blood sugar levels that are too large, causing the latter to be short of breath, not able to make enough insulin. Thus blood sugar is no longer regulated by insulin. Hyperglycemia sets in, and so does the development of diabetes. In obese people, diabetes is, therefore, the result of excess weight. Therefore, we can conclude that obesity and diabetes are intimately linked, so much so that we often speak of an epidemic of "diabetes"[15,16].

Over the past decades, many obesity drugs have been banned due to serious side effects [17]. This is why several studies are focused on traditional medicine, which has remained widespread in all regions of the developing world due to its powerful pharmacological activities, fewer side effects, and relatively low cost. In consequence, we have tried in this research to confirm the experimental results of plants known in the literature by computational chemistry techniques [18].

\section{Materials and Methods}

\subsection{The hormones responsible for obesity.}

Weight regulation and energy balance are very complex mechanisms; appetite regulation mechanisms operate at multiple levels and involve different brain organs. More precisely, the hypothalamus is a group of neurons involved in the metabolic pathways regulating hunger and satiety. These neurons have the particularity of being in direct contact with the blood system, the stomach in which digestion takes place, and finally, the intestines [19]. Moreover, insulin is a hypoglycemic hormone produced by the pancreas; it promotes the absorption of sugars after a meal; insulin also acts centrally and stimulates the production of another satiety hormone [20,21]. For instance, leptin is secreted by adipocytes that play an important role in energy balance and regulating fat mass in the body by sending a message of satiety according to certain signals. In the long run, it results in decreased appetite and an increase in energy heat recovery, leading to a decrease in obesity. Hence, we can see that obesity is a decrease in leptin that suppresses appetite [22], without forgetting to talk about the hunger hormone ghrelin, which is produced by the stomach's parietal cells. It works by direct action on the pituitary and hypothalamic systems that contain some very important neurons. These glands also activate circuits that have a specific role in appetite. However, the role of this hormone is to trigger hunger; the release of ghrelin occurs when the body needs to renew its energy. Therefore, there is a need to eat. On the other hand, its rate decreases after a meal, which reduces hunger. Moreover, ghrelin can be controlled according to feedback inhibition; it would even help fight obesity [23-24]. The regulation of appetite is a complex mechanism driven by both hormones and bacterial signals in response to the availability of nutrients. 


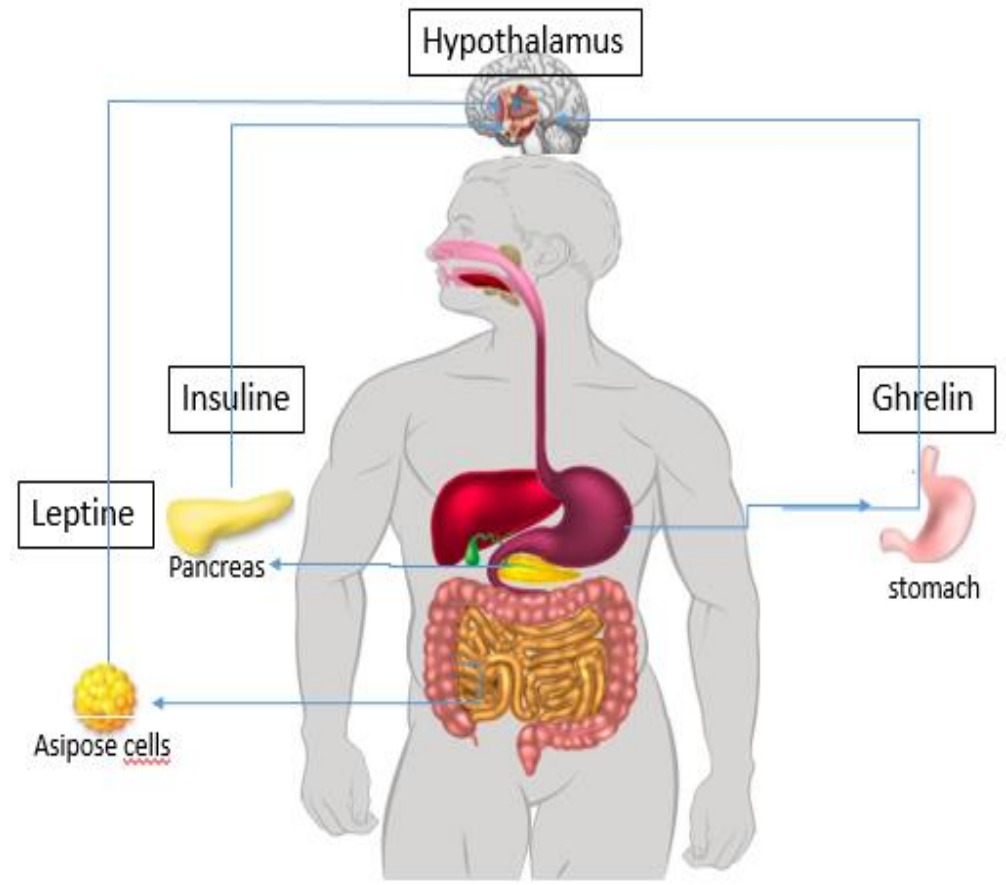

Figure 1. Appetite and hunger hormones.

\subsection{Medicinal anti-obesity plants.}

In this research, we focused on 16 medicinal plants medicinal products well known in the literature, especially in the field of traditional medicine as inhibitors of diabetes and obesity [25]. We applied the molecular docking study, molecular dynamics, and ADMET. On these plants, the molecular structures thereof are shown in the following Table 1.

\subsection{Model building and validation of selected target.}

The 3D protein structure was downloaded from RCSB (https://www.rcsb.org) PDB $\mathrm{ID}=1 \mathrm{AX} 8$ [26], and it has been analyzed and validated by calculation using the Prochek server, which gives a Ramachandran graph which makes it possible to search for the position of amino acid residues in favored regions and outliers that gives an estimate of the overall stereochemical quality of protein. Moreover, sometimes the PDB file investigated contains errors that are unknown until the corresponding revisions are made available to the structural community. Hence, the file is analyzed by the ProSA-Web program ((Protein Structure Analysis), which also indicates the total length of the 1AX8 receptor, which constitutes 130 amino acids. This service gives results instantly over a few seconds regardless of the shape of the molecules, as a Z score graph that shows the model's overall quality. In comparison, the Verify3D server was used to measure the compatibility of any protein structure with its amino acid sequence. Consequently, the ERRAT program signifies the quality factor and calculates the overall error frequency rate [27-29].

\subsection{Docking protocol.}

Thanks to the development of computer tools, scientific research is oriented towards theoretical studies more than experimental studies in different fields (such as chemical, pharmaceutical, biological); among the best-known methods, we can cite molecular docking, which is a technique that makes it possible to predict the probable interactions between two 
entities that are a binding site of a target which is generally a so-called receptor protein and an organic molecule called a ligand.

Table 1. The list of Active substances in plants and mushrooms with anti-obesogenic and antidiabetic effects.

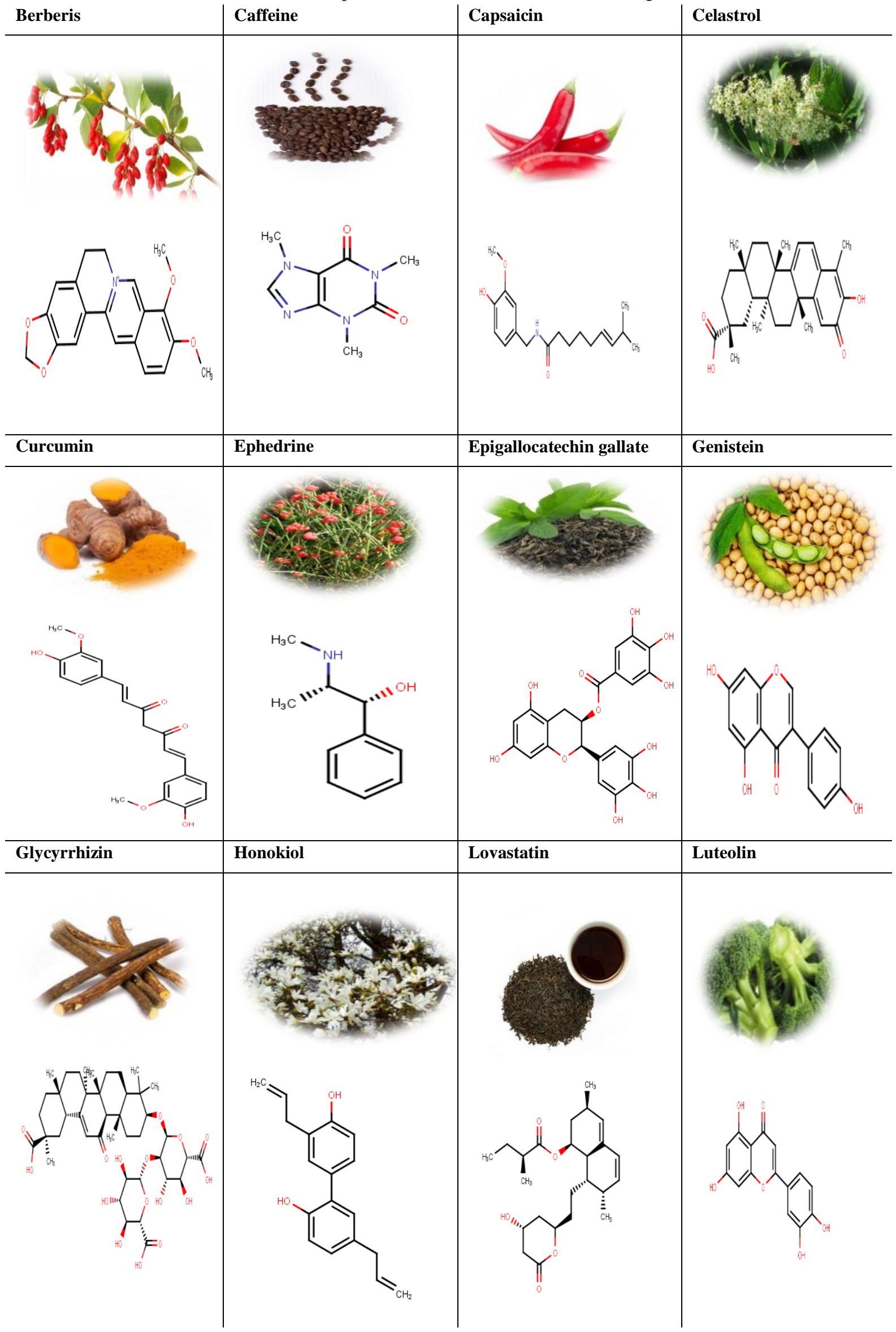




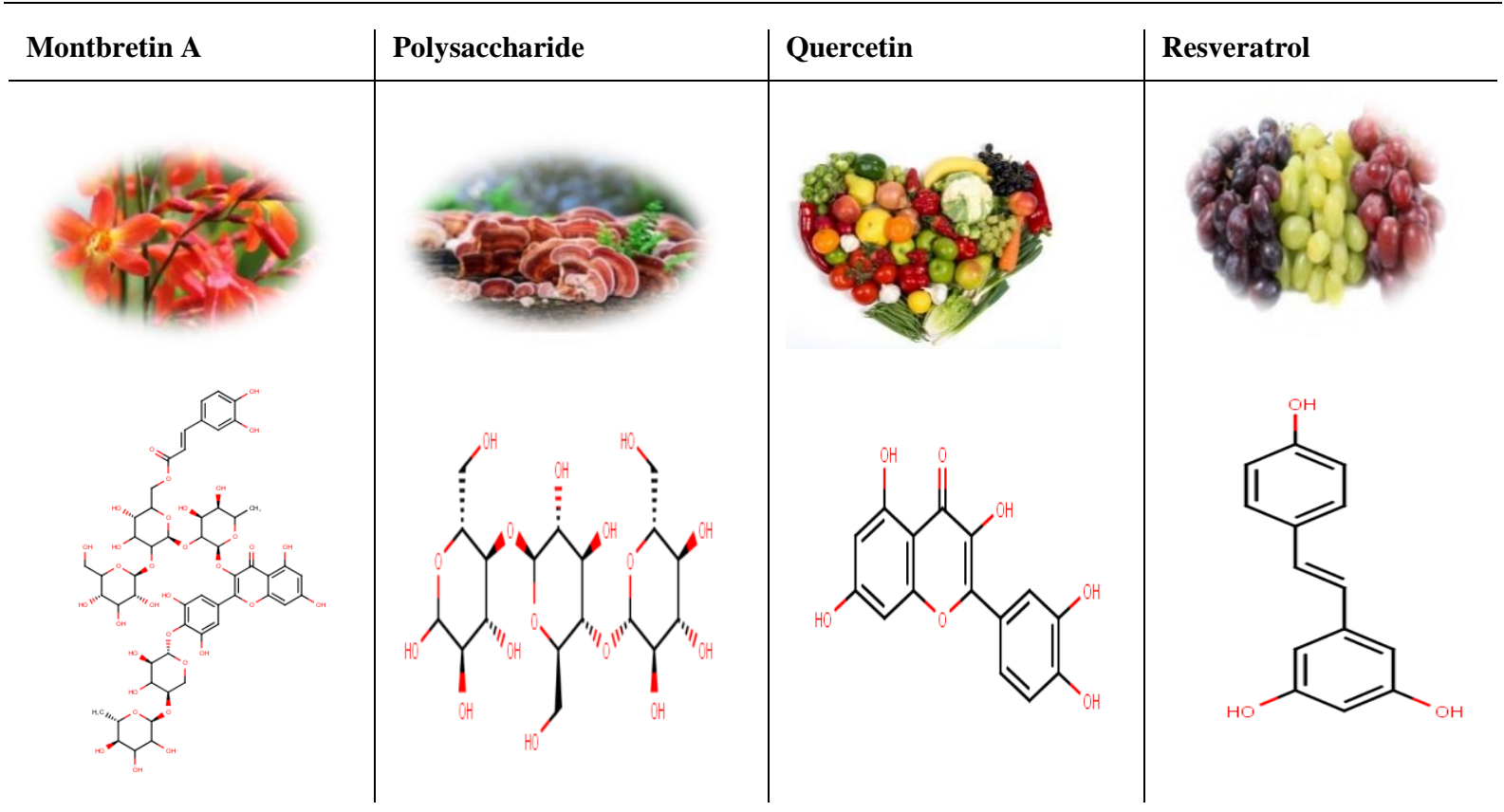

It takes place in two distinct stages: firstly optimizes the molecules using Gaussian program and downloads the obesity protein crystal structure in PDB format (ID: 1AX8; resolution: $2.40 \AA$ ), it was obtained from the RCSB Protein Data Bank (PDB, https://www.rcsb.org/), then eliminates the water molecules by using Discovery Studio software to perform the step of positioning the ligand in the chosen site of the protein designed by the SYBYL and PYMOL programs, subsequently following it up with the $2^{\text {nd }}$ step of evaluating the potential energy interactions between the ligand and the protein ). The results were visually analyzed by Discovery Studio software [30,31].

\subsection{MD simulations.}

In order to check the stability of our best docking positions, we carried out the method of molecular dynamics simulations, which allows us to analyze the physical movement of atoms and molecules, and most importantly, it is to study the stability of the complex throughout the simulation by using the Schrödinger program. Unlike the majority of docking where the protein is fixed, molecular dynamics allow this great flexibility of the protein to be taken into account as well as permits access to the most stable conformation (lowest in energy) from a docking position. Therefore, it can be used to validate or refine a docking position (ligand/protein complex obtained by docking) [32].

\subsection{ADMET study.}

As part of the search for new drugs, predict the relative properties of Absorption, Distribution, Metabolism, Excretion, Toxicity (ADME-Tox) of molecules, chemoinformatics is regularly used in order to improve their pharmacokinetic properties by eliminating those that would not be good drug candidates [33]. Therefore, in this study, we transformed the molecules in SMILES format, and we applied the pkCSM webserver to each molecule, which provides ADMET information. In addition, for a drug to be effective and bio-available, it must also have other characteristics, and he must also follow rules which are called Lipinski's rules which were calculated by using the Swissadme server (http://www.swissadme.ch/) [34,35]. 


\section{Results and Discussion}

\subsection{Protein structure validation.}

The 3D structure (Figure 2a) in PDB format was submitted for validation using the various servers. According to the next check, $94.7 \%$ of the tailings were located in the most favored region on the Ramachandran graph (Figure $2 b$ ) as well as the stereochemical validation was performed by using the ProSA server, which shows a graph with X-ray crystallography and spectroscopy areas in light and dark blue respectively and a Z-score was found at -4.56 (Figure 2c). Consequently, the VERIFY3D graph indicates that $77.69 \%$ of the residues had a $3 \mathrm{D}-1 \mathrm{D}$ score $\geq$ of 0.2 , suggesting a good model quality (Figure $2 \mathrm{~d}$ ). While from the ERRAT graph, we found that the quality factor is highly estimated at 96.61 (Figure 2e). These validation tools represent the satisfaction and reliability of the protein structure modeled for carrying out molecular docking.
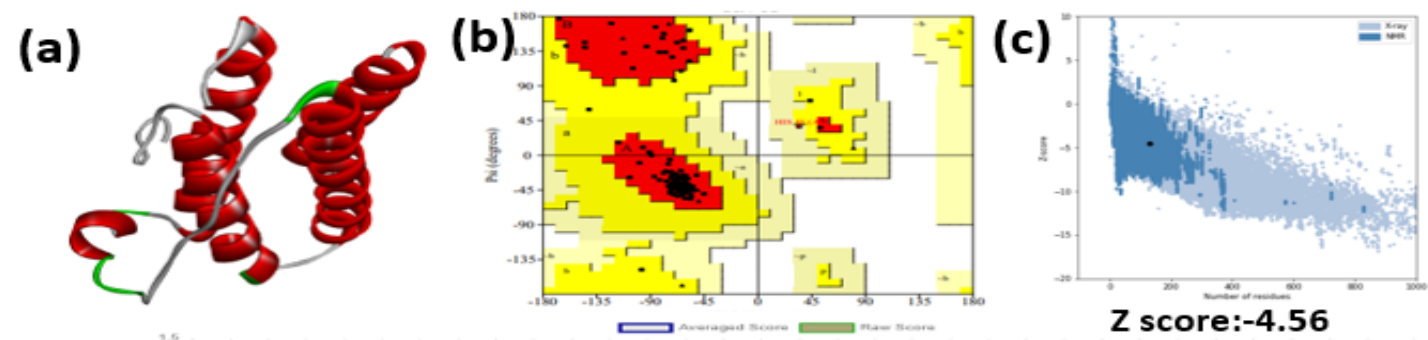

(d)

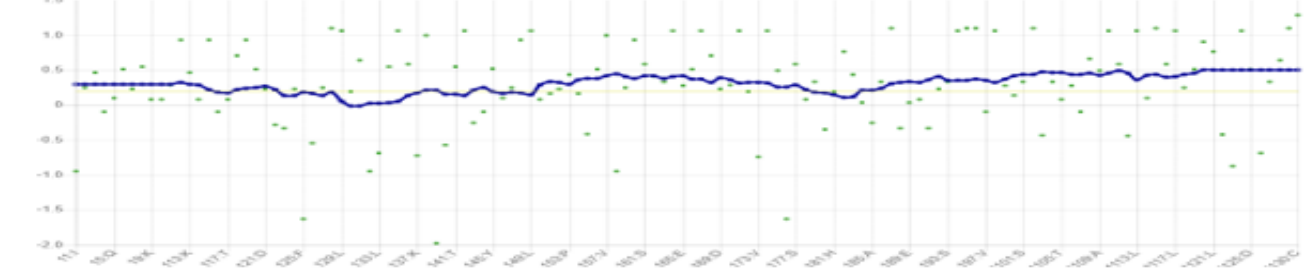

(e)

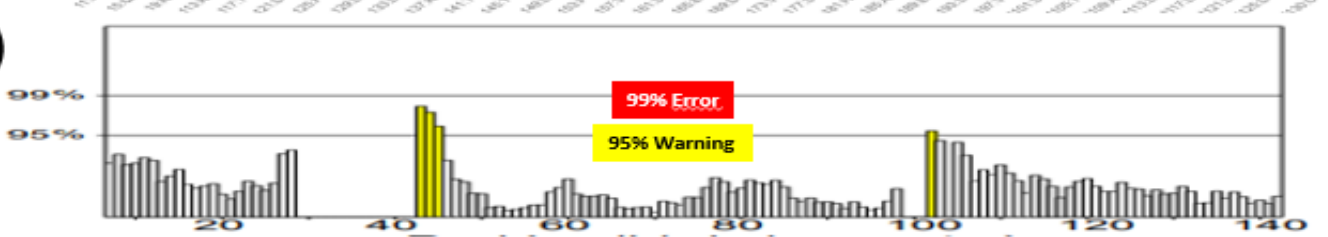

Figure 2. Structure prediction \& validation of 1AX8 Receptor. (a) Modeled 3D structure of 1AX8 receptor; (b) Ramachandran plot of 1AX8 receptor generated by pro check server; (c) Z-Score plot for the modeled 1AX8;

(d) Verify 3D; (e) Error frequency plot generated by ERRAT server.

\subsection{Molecular docking studies.}

In this study, we performed molecular docking to identify therapeutic agents against obesity, and it is a technique that makes it possible to predict or study interactions that are the main factors having a significant impact on the affinity of a ligand for a receptor. In addition, this study helps us to propose some plants as a treatment for weight loss. The results displayed in Table 2 indicate that plants such as Quercetin[36], Honokiol [37], Curcumin [38], Capsaicin [39], Caffeine [40] et Berberis [41] exhibit good interactions with the 1AX8 protein (Resolution: $2.40 \AA$ ), we visualized that for Quercetin and Honokiol there is the presence of hydrogen bonds which is considered among the significant factors of protein-ligand stability. Furthermore, the distances of its bonds are less than $3 \AA$, which is a strong hydrogen bond, and GLN A: 134 from curcumin and ASP A: 135 from Capasaicin cause hydrogen bonds with OH groups that show the importance of these amino acids. While for Caffeine and Berberis, we have marked the absence of hydrogen bonds. However, there are other interactions such as pi- 
Alkyl with the residue TRP A:138 for caffeine, and carbon-hydrogen bond with ASP A: 40; PHE A: 41; ILE A: 42; ASP A: 135; GLY A: 131 for Barberis, this is what confirms the effectiveness of these plants against obesity is in the literature Quercetin decreases body weight and regulates lipid metabolism, Other studies show that turmeric is known to be effective in treating and preventing diabetes likewise accelerates weight loss, not to mention that there are British researchers who have shown that caffeine may fight obesity by regulating lipid metabolism and inhibiting adipocyte differentiation.

Table 2. Different interactions and key residues (amino acids) for more active molecules.

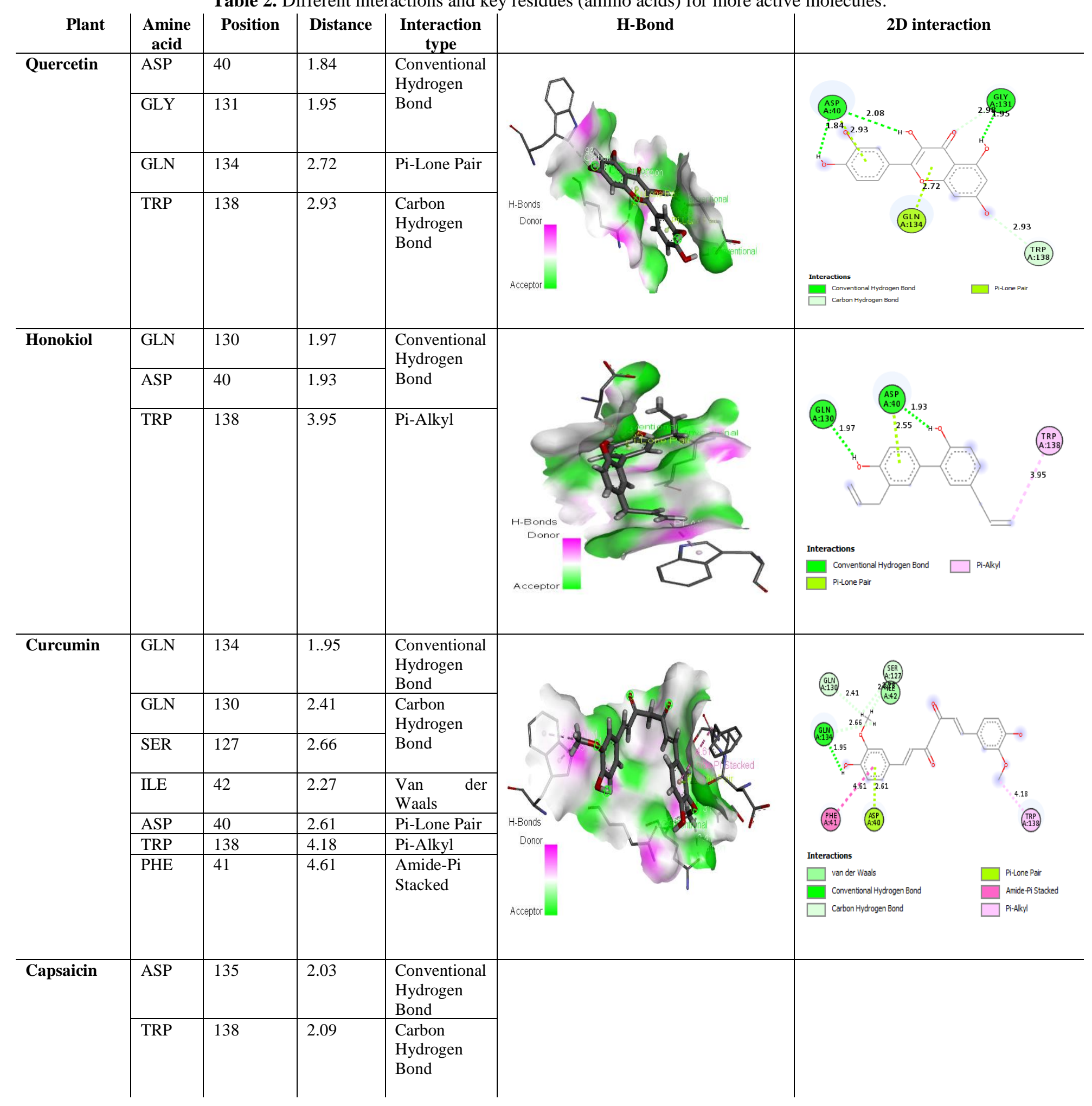




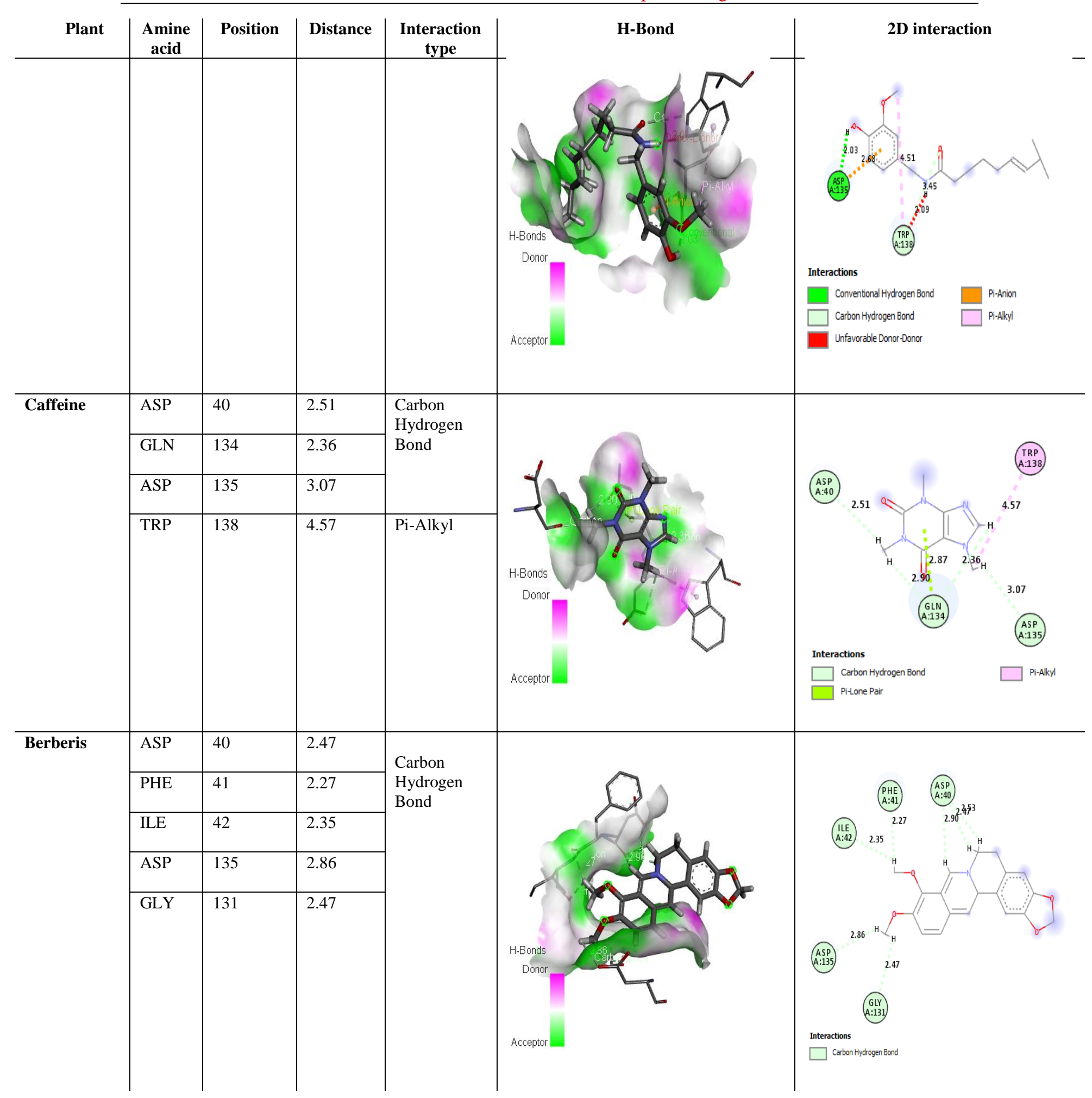

On the other hand, molecular docking studies for the rest of the plants give unfavorable donor-donor interactions or acceptors (Table 3), confirming research decisions to stop the marketing of some of its plants. However, side effects of ephedrine such as heart attacks and cardiovascular problems were led by the FDA in the United States to give the order to stop the 4th marketing of food supplements containing the latter, which allows us to hypothesize that other plants have negative health effects [42].

Further, we thought of comparing our results (Table 4) with the drug Xenical which is available in pharmacies. 
Table 3. Different interactions and key residues (amino acids) for inactive molecules.

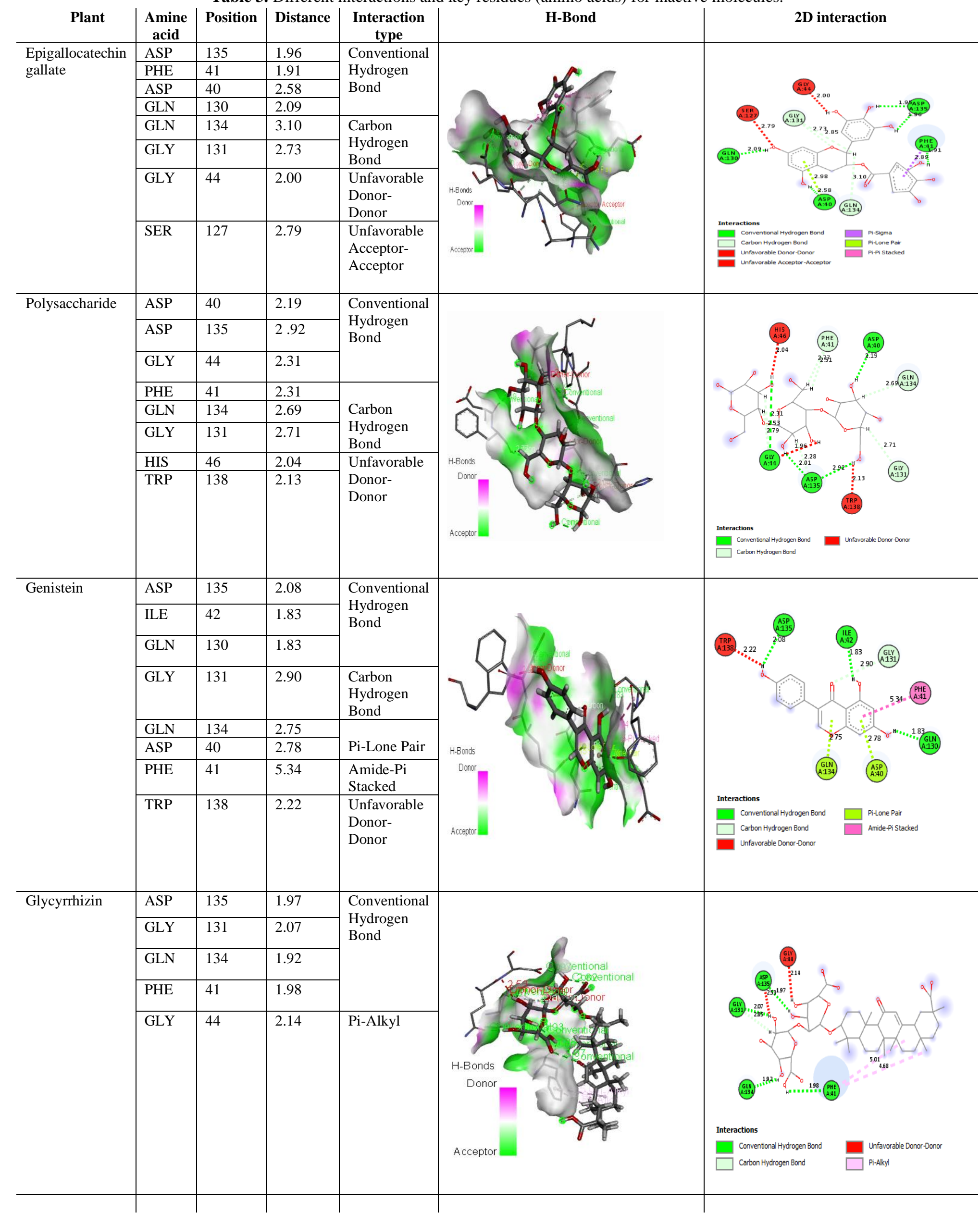




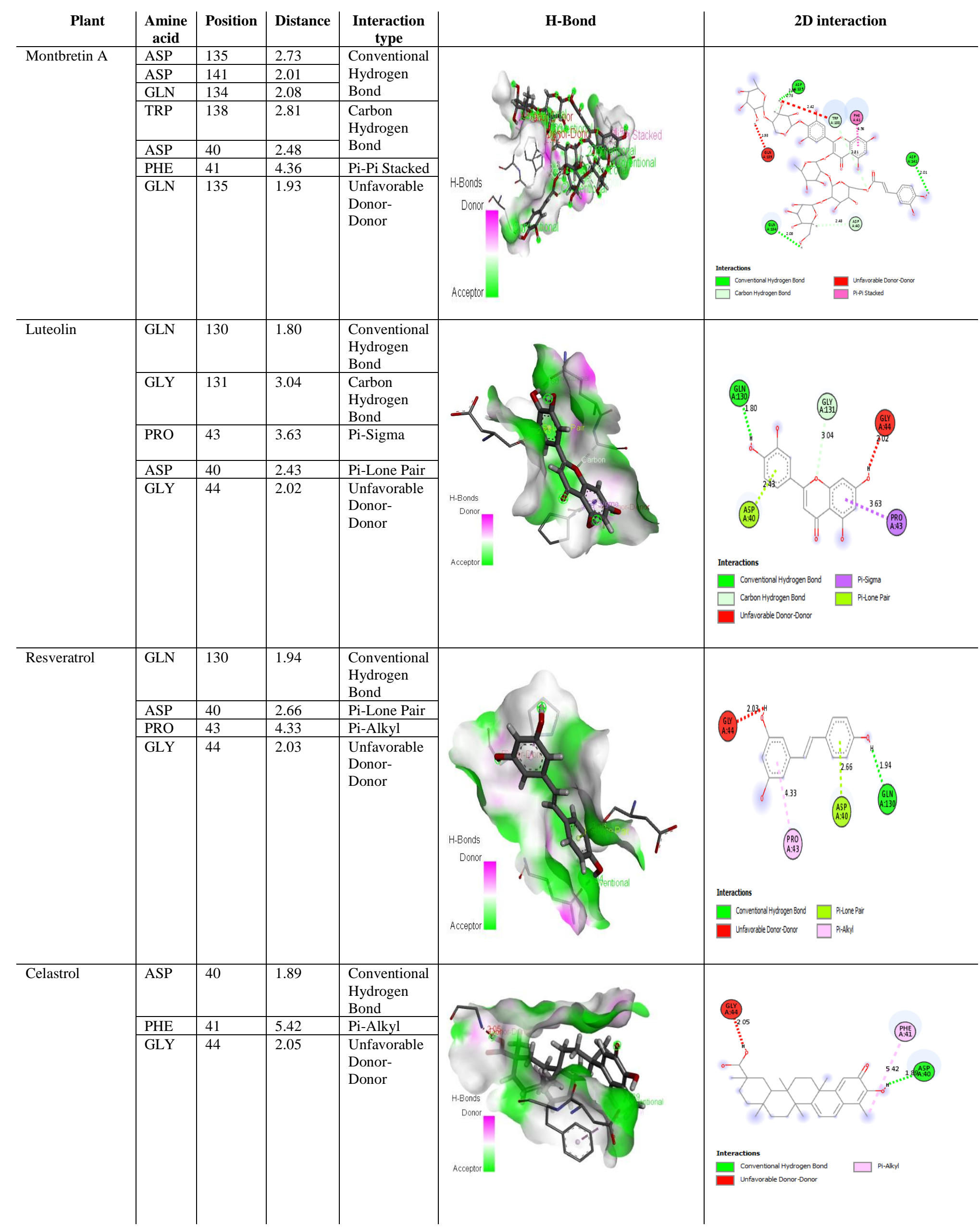




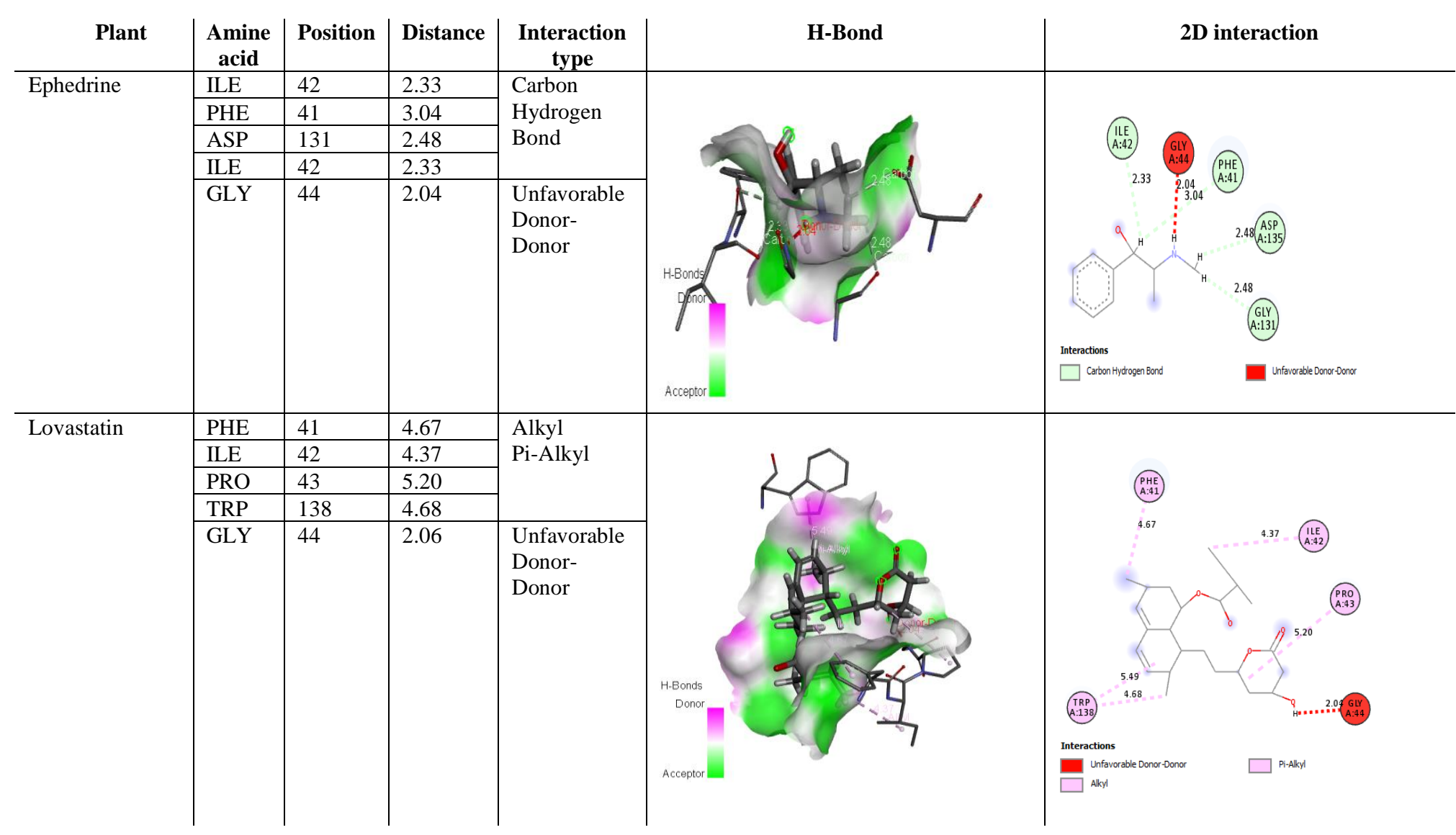

We can especially cite this drug which has shown that it could allow weight loss while reducing cases of diabetes [43-46]. Moreover, we noticed in our study that the quercitrin plant has good interactions with this drug. Therefore, this plant has provided very satisfactory results.

Table 4. Different interactions and key residues (amino acids) for Xenical.

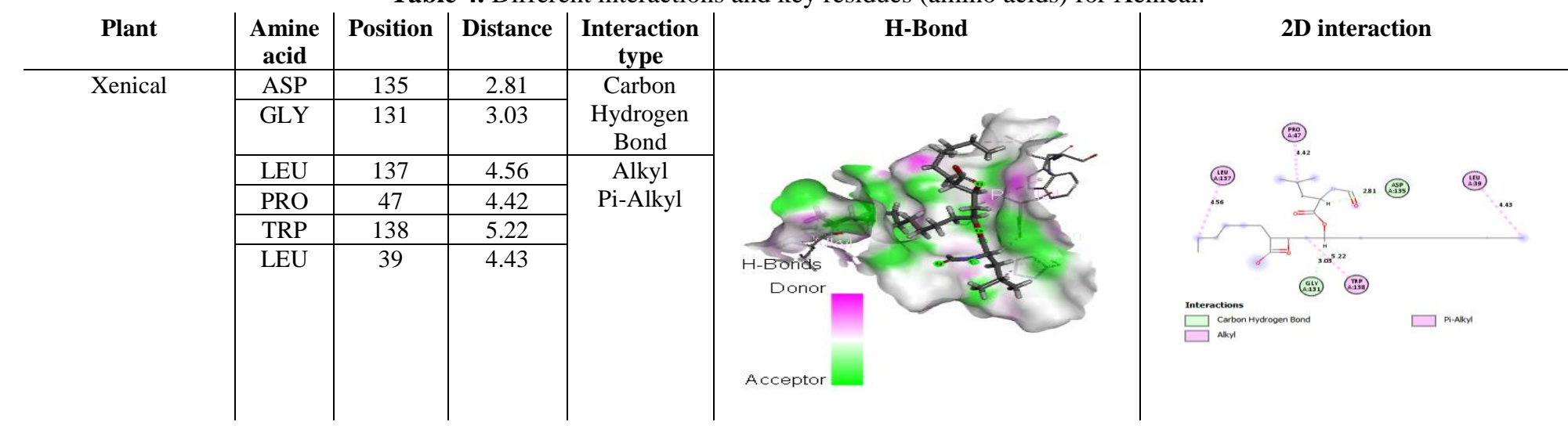

\subsection{ADMET.}

Oral administration is the most convenient route for patients to receive drugs. When the drug is administered orally, it has to be absorbed across the epithelium of the small intestine. The results presented in Table 4 revealed that all the compounds showed high absorption above $70 \%$, except Glycyrrhizin, Montbretin A, and Polysaccharide, which presented $0 \%$ absorption. It demonstrates that these molecules cannot absorb at the level of the human intestine. So for Epigalloc, it presents a very low absorption of $45.33 \%$ [47].

The $\operatorname{LogBB}$ is a commonly used parameter to express the extent of drug passage across the blood-brain barrier. Experimental determination of BBB permeation is time-consuming, 
expensive, and requires a sufficient amount of product. For this reason, in silico study of compounds for $\log \mathrm{BB}$ is to be examined even before chemical synthesis.

The BBB is defined as the ratio of the brain to the blood concentration of a compound at a steady state. On the other hand, peripherally acting drugs must have a limited ability to cross the BBB to avoid adverse CNS effects. From the results of table 5, we can see that the compounds Glycyrrhi, Montbretia, Polysaccharide, and Epigalloc that have a low absorption as also have a low value of $\log \mathrm{BB}$ that shows are poor distribution to the brain and very low values of $\log$ PS which means are difficult to move in the CNS [48].

The enzymatic metabolism indicates the chemical biotransformation of a drug in the body, which plays a crucial role in converting drug compounds. The cytochrome CYP plays a major role in drug metabolism, containing several families like 2D6 and 3A4. The results presented in Table 5 showed that only berberis, Celastrol, Honokiol, Lovastatin, and Xenical were found to be the substrate of CYP3A4 and Capsaicin Curcumin, Lovastatin, Luteolin, and Quercetin were found to be the inhibitor of CYP3A4 [49-50].

Furthermore, it can be observed from Table 6 that 6 compounds do not respect the Lipinski rules, Xenical, Epigall, Glycyrrhizin, MontbretinA, Polysaccharide and Celastrol, where all values of $\log \mathrm{P}<5$, molecular weight $<500, \mathrm{HBA}<10$ and $\mathrm{HBD}<5$ and $\mathrm{RB}<10$. On the other hand, the other compounds respect these norms [51].

Table 5. Results of the ADMET test with pKCSM of all compounds.

\begin{tabular}{|c|c|c|c|c|c|c|c|c|c|c|}
\hline & \multirow{4}{*}{$\begin{array}{c}\text { Absorption } \\
\begin{array}{c}\text { Intestinal } \\
\text { absorption } \\
\text { (human) }\end{array} \\
\begin{array}{c}\text { Numeric (\% } \\
\text { Absorbed ) }\end{array} \\
\end{array}$} & \multirow{2}{*}{\multicolumn{2}{|c|}{ Distribution }} & \multirow{3}{*}{\multicolumn{4}{|c|}{$\begin{array}{c}\text { Metabolism } \\
\text { CYP }\end{array}$}} & \multirow{4}{*}{ 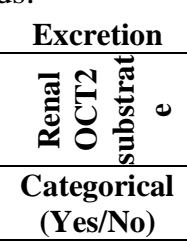 } & \multirow{2}{*}{\multicolumn{2}{|c|}{ Toxicity }} \\
\hline & & & & & & & & & & \\
\hline & & \multirow{2}{*}{ 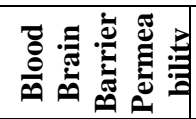 } & \multirow{2}{*}{ 忌焉 } & & & & & & \multirow{2}{*}{ 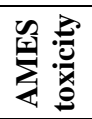 } & \multirow{2}{*}{ 产 } \\
\hline & & & & \multicolumn{2}{|c|}{ Substrate } & \multicolumn{2}{|c|}{ Inhibitor } & & & \\
\hline berberis & 100 & 0.58 & -1.692 & No & Yes & yes & no & yes & No & no \\
\hline Caffeine & 98.90 & -0.26 & -2.94 & No & No & No & No & No & yes & Yes \\
\hline Curcumin & 81.83 & -0.29 & -2.98 & No & no & No & yes & No & No & no \\
\hline Ephedrine & 90.73 & -0.11 & -2.42 & No & no & No & no & No & No & Yes \\
\hline Epigalloc & 45.33 & -2.39 & -4.15 & No & no & No & no & No & yes & no \\
\hline Genistein & 93.39 & -1.01 & -2.21 & No & no & No & no & no & No & no \\
\hline Glycyrrhizin & 0 & -2.01 & -3.83 & No & no & No & no & No & No & no \\
\hline Honokiol & 91.82 & -0.14 & -1.33 & no & Yes & $\mathrm{No}$ & no & No & no & no \\
\hline Quercetin & 74.08 & -1.49 & -3.40 & No & No & No & yes & No & Yes & no \\
\hline resveratrol & 88.49 & -0.17 & -2.02 & No & No & No & No & No & No & no \\
\hline Xenical & 90.315 & -1.013 & -3.131 & No & Yes & No & No & Yes & No & Yes \\
\hline
\end{tabular}

Table 6. Lipinski's role of all compounds in the dataset.

\begin{tabular}{|c|c|c|c|c|c|}
\hline Compounds & Molecular weight (g/mol) & $\log P$ & H-bond acceptors & H-bond donors & Rotatable bonds \\
\hline Berberis & 336.36 & 3.62 & 4 & 0 & 2 \\
\hline Caffeine & 194.19 & -0.07 & 3 & 0 & 0 \\
\hline Capsaicin & 305.41 & 3.58 & 3 & 2 & 2 \\
\hline Celastrol & 450.61 & 5.94 & 4 & 2 & 1 \\
\hline Curcumin & 368.38 & 3.20 & 6 & 2 & 8 \\
\hline Ephedrine & 165.23 & 0.93 & 2 & 2 & 3 \\
\hline Epigall & 458.37 & 1.17 & 11 & 8 & 4 \\
\hline Genistein & 270.24 & 2.67 & 5 & 3 & 1 \\
\hline Glycyrrhizin & 822.93 & 2.80 & 16 & 8 & 7 \\
\hline Honokiol & 266.33 & 4.98 & 2 & 2 & 5 \\
\hline Lovastatin & 404.54 & 4.26 & 5 & 1 & 7 \\
\hline Luteolin & 286.24 & 2.53 & 6 & 4 & 1 \\
\hline
\end{tabular}




\begin{tabular}{c|c|c|c|c|c} 
Compounds & Molecular weight $\mathbf{( g / m o l})$ & LogP & H-bond acceptors & H-bond donors & Rotatable bonds \\
\hline MontbretinA & 1229.06 & -4.12 & 33 & 19 & 17 \\
\hline Polysaccharide & 504.44 & -6.88 & 16 & 11 & 7 \\
\hline Quercetin & 302.24 & 1.54 & 7 & 5 & 1 \\
\hline resveratrol & 228.24 & 3.13 & 3 & 3 & 2 \\
\hline Xenical & 495.745 & 6.88 & 5 & 1 &
\end{tabular}

\subsection{MD simulations.}

Docking studies do not hold the protein flexible. To estimate the exact binding orientation and ligand-receptor complex stability, we need to call MD simulations using two critical parameters, which are RMSD and RMSF, under physiological, environmental conditions of pressure, and temperature.

In this work, we have evaluated the stability of docking complexes relating to Quercetin by molecular dynamics during 100ns.

At the start of the simulation, the RMSD curve of the protein backbone and that of the ligand increases considerably until it reaches a maximum value and stabilizes around a value of $3.5 \AA$ from $30 \mathrm{~ns}$ until the end of the simulation (Figure 3 ). These results confirm the stability of the selected complex, and the ligand does not make a large conformational change.

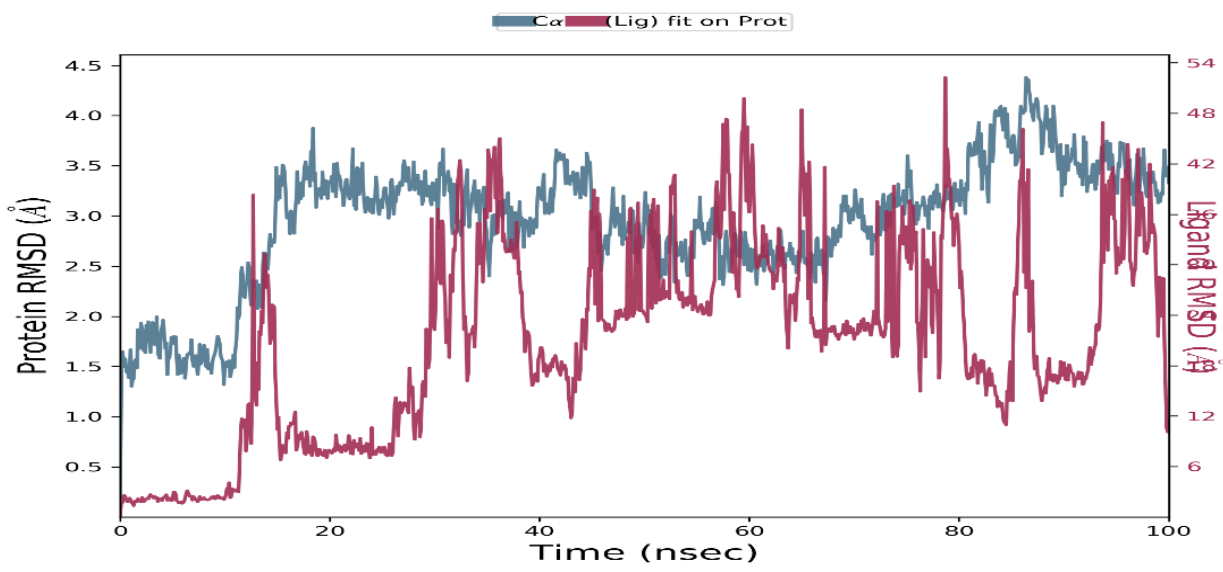

Figure 3. RMSD of backbone atoms relative Quercetin complexes during $100 \mathrm{~ns}$ MD.

We also followed the evolution of RMSF of the protein; Figure 4 shows four peaks but with intensities generally not exceeding 6.4A, indicating weak local changes to characterize local changes in the protein chain (Figure 4). This result shows a weak fluctuation of the complex within the receptor.

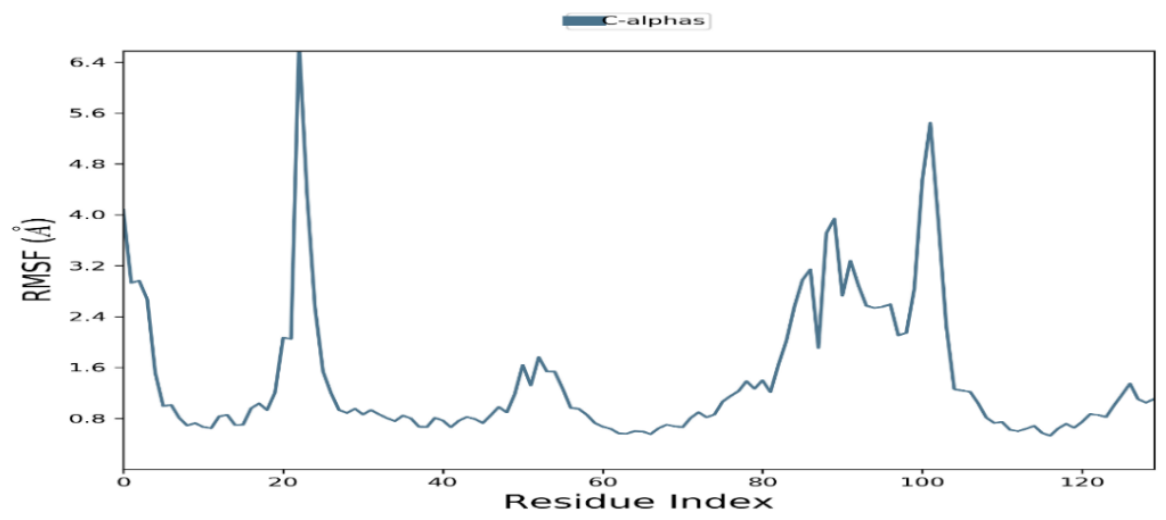

Figure 4. RMSF plot of obesity protease at 100 ns time scale (Quercetin). 
The MD simulation results show that during the 100 ns simulation, the RMSD of the protein shows a deviation between 1.6 $\AA$ and $3.2 \AA$. As well as the RMSD value of the ligand shows deviation from $3 \AA$ up to a max of $11 \AA$. The RMSF of protein fluctuations was less than $4.8 \AA$; high fluctuations were recorded between 20 -30 residue regions. The RMSD and RMSF graphs are shown in Figure 5 and Figure 6, successively [31].

Protein-Ligand RMSD

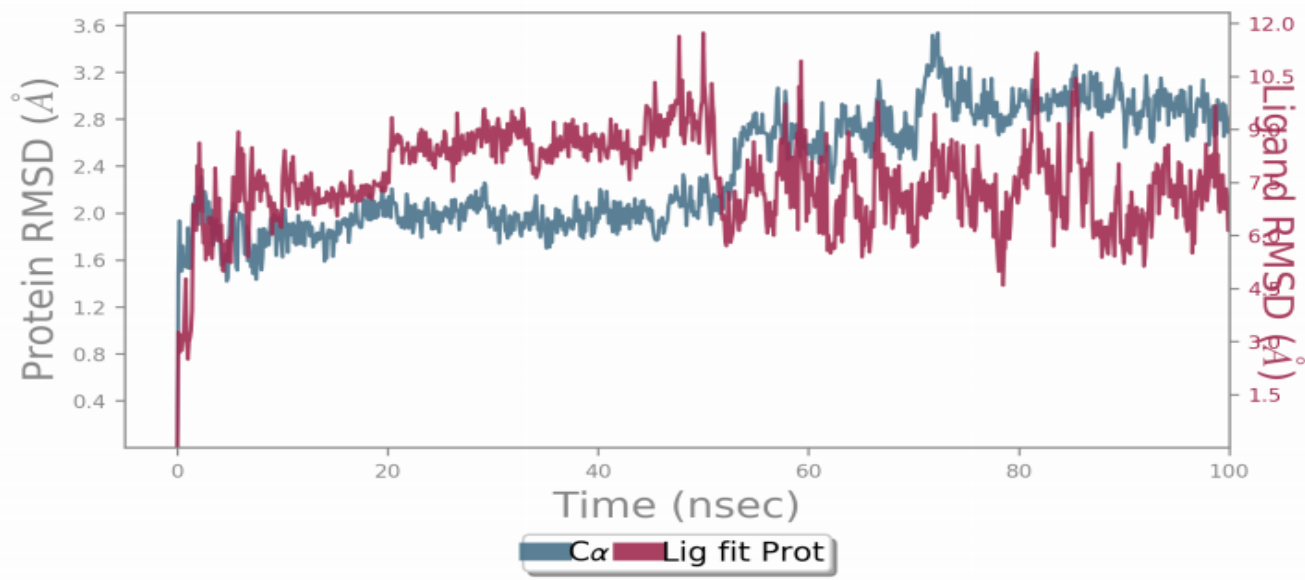

Figure 5. RMSD of backbone atoms relative Xenical complexes during $100 \mathrm{~ns}$ MD.

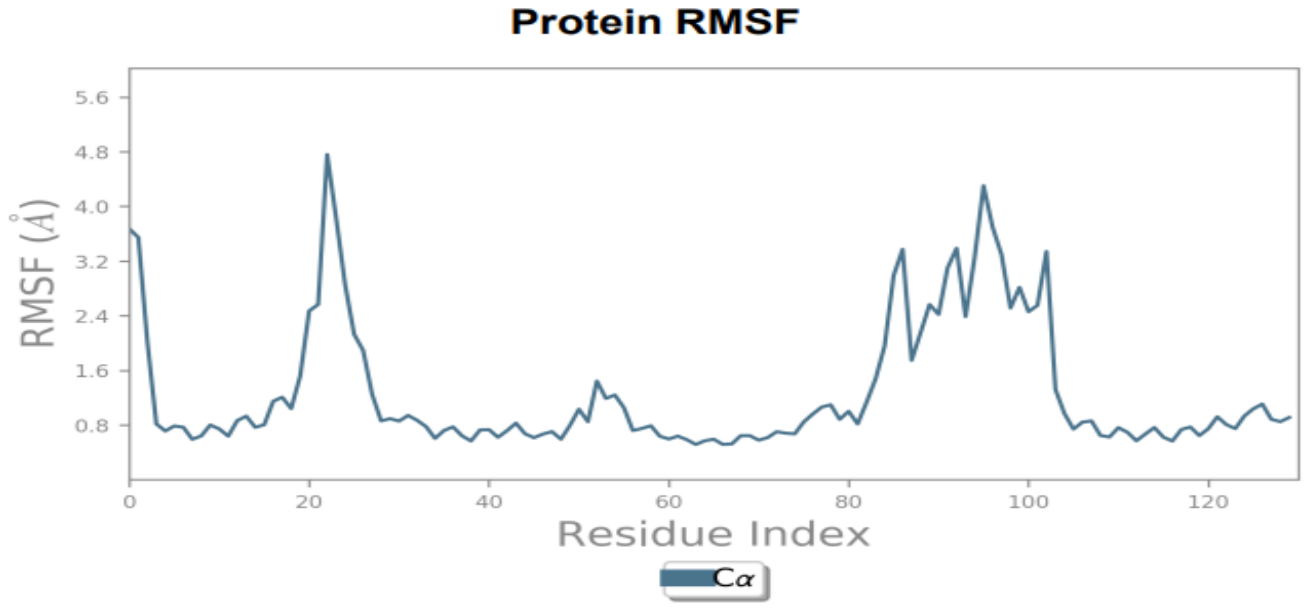

Figure 6. RMSF plot of obesity protease at 100 ns time scale (Xenical).

According to Figure 7, the results of Molecular dynamics are very satisfactory; the proteins are very flexible and exist in several conformations in equilibrium between them. Unlike most docking, where the protein is fixed, molecular dynamics make it possible to consider this great flexibility of the protein. It can therefore be used to validate or refine a docking position (ligand/protein complex). These molecular dynamics simulation results proved that the docking of the compounds Xenical and Quercitin were performed correctly in the active site; this also gave the idea that these two compounds formed stable complexes, which can translate that the results are satisfactory.

\section{Conclusions}

We conclude that the most important result of this research is that we were able to design and propose a plant as a treatment for obesity. The results of this compound are satisfactory. In addition, the study of molecular docking helps us with the ADMET to offer this 
plant as a treatment for weight loss; they indicate good interactions and remarkable stability compared to the drug Xenical. Therefore this plant reduces the time and cost of the synthesis.

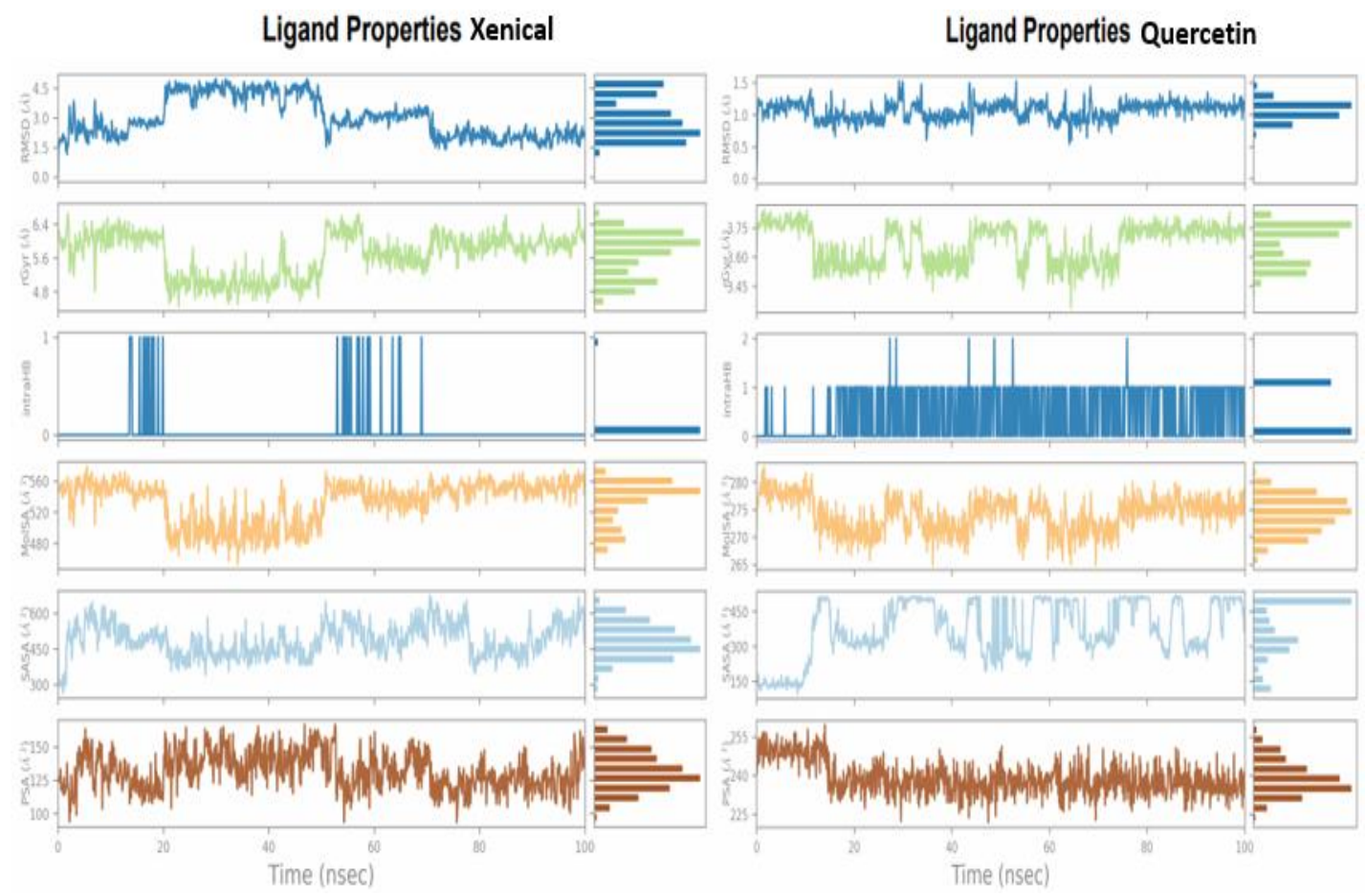

Figure 7. ligand properties for Xenical and Quercetin.

\section{Funding}

This research received no external funding.

\section{Acknowledgments}

The authors would like to thank the anonymous reviewers for their valuable comments and suggestions to improve the paper's quality.

\section{Conflicts of Interest}

We wish to confirm that there are no known conflicts of interest associated with this publication, and there has been no significant financial support for this work that could have influenced its outcome.

\section{References}

1. Bradley Dexter, S.; Kavanagh Salmond, K.; Payne, L.; Chia, M.C.; Di Ruggiero, E.; Mahato, S. The Art and Science of a Strategic Grantmaker: The Experience of the Public Health Agency of Canada's Innovation Strategy. Can J Public Health 2021, 112, 186-203, https://doi.org/10.17269/s41997-021-00512-9.

2. PAN, X.; ZHAO, L.; LUO, J. Access to Bike Lanes and Childhood Obesity: A Systematic Review and Meta-analysis - Pan - Obesity Reviews - 2021, 22, e13042, https://doi.org/10.1111/obr.13042.

3. Sharma, H.; Chandola, H.M. Ayurvedic Concept of Obesity, Metabolic Syndrome, and Diabetes Mellitus. The Journal of Alternative and Complementary Medicine 2011, 17, 549-552, https://doi.org/10.1089/acm.2010.0690.

4. MA, S.; XI, B.; YANG, L. Trends in the Prevalence of Overweight, Obesity, and Abdominal Obesity among Chinese Adults between 1993 and 2015 | International Journal of Obesity, 2021, 45, n 2,. 427-437, https://doi.org/10.1038/s41366-020-00698-x.

5. WHO Expert Consultation Appropriate Body-Mass Index for Asian Populations and Its Implications for Policy and Intervention Strategies. Lancet 2004, 363, 157-163, https://doi.org/10.1016/S01406736(03)15268-3. 
6. Mkuu, R.; Barry, A.; Yonga, G.; Nafukho, F.; Wernz, C.; Gilreath, T.; Chowdhury, M.A.B.; Shevon Harvey, I. Prevalence and Factors Associated with Overweight and Obesity in Kenya. Preventive Medicine Reports 2021, 22, 101340, https://doi.org/10.1016/j.pmedr.2021.101340.

7. H. Hajji et al., « Catastrophic Collision Between Obesity and COVID-19 Have Evoked the Computational Chemistry for Research in Silico Design of New CaMKKII Inhibitors Against Obesity by Using 3D-QSAR, Molecular Docking, and ADMET », Orbital: Electron. J. Chem., vol. 13, no 4, p. 316-327, oct. 2021, doi: 10.17807/orbital.v13i4.1608.

8. Hagerty, M.P.; Walker-Santiago, R.; Tegethoff, J.D.; Stronach, B.M.; Keeney, J.A. Tobacco Use Is Associated with More Severe Adverse Outcomes Than Morbid Obesity after Aseptic Revision TKA. J Knee Surg 2021, https://doi.org/10.1055/s-0041-1731459.

9. Schröder, H.; Morales-Molina, J.A.; Bermejo, S.; Barral, D.; Mándoli, E.S.; Grau, M.; Guxens, M.; de Jaime Gil, E.; Álvarez, M.D.; Marrugat, J. Relationship of Abdominal Obesity with Alcohol Consumption at Population Scale. Eur J Nutr 2007, 46, 369-376, https://doi.org/10.1007/s00394-007-0674-7.

10. Charlotte, A.S. Body Weight Status of Adults: United States, 1997-98 - Google Livres.

11. Lopez, R.P. Neighborhood Risk Factors for Obesity. Obesity 2007, 15, 2111-2119, https://doi.org/10.1038/oby.2007.251.

12. Bianchini, F.; Kaaks, R.; Vainio, H.; Weight Control and Physical Activity in Cancer Prevention - Obesity Reviews 2002, 5- 8, https://doi.org/10.1046/j.1467-789X.2002.00046.x.

13. Blair, S.N.; Nichaman, M.Z. The Public Health Problem of Increasing Prevalence Rates of Obesity and What Should Be Done About It. Mayo Clinic Proceedings 2002, 77, 109-113, https://doi.org/10.4065/77.2.109.

14. Yaribeygi, H.; Maleki, M.; Sathyapalan, T. Obesity and Insulin Resistance: A Review of Molecular Interaction. Current Molecular Medicine 2021, 21, 3, 182-193, https://doi.org/10.2174/1566524020666200812221527.

15. Smati, S.; Tramunt, B.; Wargny, M. Relationship between Obesity and Severe COVID-19 Outcomes in Patients with Type 2 Diabetes: Results from the CORONADO Study - Smati - Diabetes, Obesity and Metabolism 2021, 23, 2, 391-403.

16. Smyth, S.; Heron, A. Diabetes and Obesity: The Twin Epidemics | Nature Medicine 2006, 12, 1, 75-80, https://doi.org/10.1038/nm0106-75.

17. Hajji, H.; Aanouz, I.; Khatabi, K.E.; Lakhlifi, T.; Ajana, M.A.; Bouachrine, M. 2D-QSAR Study of the Anti-Obesity Activity for the Compounds Based on 2-Anilino, 4-Aryl Pyrimidines and 2,4-Diaryl 7Azaindoles Using Statistical Methods. Journal of Analytical Sciences and Applied Biotechnology 2020, 2, 2-1, 23-31, https://doi.org/10.48402/IMIST.PRSM/jasab-v2i1.21121.

18. Tirthani, E.; Quartuccio, M. Non-dieting Approaches To Treatment Of Obesity. In StatPearls; StatPearls Publishing: Treasure Island (FL) 2021.

19. Wang, L.; Yu, C.-C.; Li, J.; Tian, Q.; Du, Y.-J. Mechanism of Action of Acupuncture in Obesity: A Perspective From the Hypothalamus. Frontiers in Endocrinology 2021, 12, 325, https://doi.org/10.3389/fendo.2021.632324.

20. Jaksic, M.; Martinovic, M. Relationship between Insulin-like Growth Factor-1, Insulin Resistance and Metabolic Profile with Pre-Obesity and Obesity in Children 2021, 34, 3, 301-309. https://doi.org/10.1515/jpem-2020-0447.

21. Wever, M.; Van Meer, F. Growth-differentiation-factor 15 Levels in Obese and Healthy Pregnancies: Relation to Insulin Resistance and Insulin Secretory Function - Andersson-Hall. Clinical Endocrinology 2021, https://doi.org/10.1111/cen.14433.

22. Wever, M.C.M.; van Meer, F.; Charbonnier, L.; Crabtree, D.R.; Buosi, W.; Giannopoulou, A.; Androutsos, O.; Johnstone, A.M.; Manios, Y.; Meek, C.L. Associations between Ghrelin and Leptin and Neural Food Cue Reactivity in a Fasted and Sated State. NeuroImage 2021, 240, 118374, https://doi.org/10.1016/j.neuroimage.2021.118374.

23. Obradovic, M.; Sudar-Milovanovic, E.; Soskic, S.; Essack, M.; Arya, S.; Stewart, A.J.; Gojobori, T.; Isenovic, E.R. Leptin and Obesity: Role and Clinical Implication. Front Endocrinol (Lausanne) 2021, 12, 585887, https://doi.org/10.3389/fendo.2021.585887.

24. Malhotra, S.; Levitsky, L.L. Ghrelin: Growth Hormone Release to Hunger Hormone to Glucose Regulation: Lessons From a Rare Genetic Disorder. The Journal of Clinical Endocrinology \& Metabolism 2021, 106, e375-e376, https://doi.org/10.1210/clinem/dgaa762.

25. Martel, J.; Ojcius, D. Anti-Obesogenic and Antidiabetic Effects of Plants and Mushrooms. Nature Reviews Endocrinology 2017, 13, 3, 149-160, https://doi.org/10.1038/nrendo.2016.142.

26. Boateng, K. Bioinformatics Workshop 2008 Human Obesity Protein-Leptin (1ax8).

27. Laskowski, R.A.; MacArthur, M.W.; Moss, D.S.; Thornton, J.M. PROCHECK: A Program to Check the Stereochemical Quality of Protein Structures. J Appl Cryst 1993, 26, 283-291, https://doi.org/10.1107/S0021889892009944.

28. Sehgal, S.A.; Mirza, A.H.; Tahir, R.A.; Mir, A. Quick Guideline for Computational Drug Design. Bentham Science Publishers 2018; ISBN 978-1-68108-603-3. 
29. Srivastava, U.; Singh, G. Comparative Homology Modelling for HPV Type 16 E 7 Proteins by Using MODELLER and Its Validations with SAVS and ProSA Web Server. Journal of Computational Intelligence in Bioinformatics 2013, 6, 27, https://doi.org/10.37622/JCIB/6.1.2013.27-33.

30. Wang, Z.; Wang, N.; Han, X. Interaction of Two Flavonols with Fat Mass and Obesity-Associated Protein Investigated by Fluorescence Quenching and Molecular Docking: Journal of Biomolecular Structure and Dynamics 2018, 36, 13, 3388-3397, https://doi.org/10.1080/07391102.2017.1388287.

31. Al, H.H. Antiproliferative Activity: Discovery of New Benzoxanthenes Derivatives by Using Various Statistical Methods 2D/3D-QSAR and Molecular Docking. RHAZES: Green and Applied Chemistry 2021, 12, 40-59, https://doi.org/10.48419/IMIST.PRSM/rhazes-v12.26038.

32. Modanwal, S.; Tiwari, S.; Mishra, N. Drug Design against Obesity Using Computer Aided Approach. International Journal of Advanced Science and Technology 2020, 4, 8798-8809.

33. Pratama, M.R.F.; Poerwono, H.; Siswodiharjo, S. ADMET Properties of Novel 5-O-Benzoylpinostrobin Derivatives. Journal of Basic and Clinical Physiology and Pharmacology 2019, 30, https://doi.org/10.1515/jbcpp-2019-0251.

34. Pratama, M.R.F.; Poerwono, H.; Siswodihardjo, S. Molecular Docking of Novel 5-O-Benzoylpinostrobin Derivatives as Wild Type and L858R/T790M/V948R Mutant EGFR Inhibitor. Journal of Basic and Clinical Physiology and Pharmacology 2019, 30, https://doi.org/10.1515/jbcpp-2019-0301.

35. H. Hajji et al., « Assessment of asthma treatment against SARS CoV-2 by using a computer approach », E3S Web Conf., vol. 319, p. 01024, 2021, https://doi.org/10.1051/e3sconf/202131901024.

36. Aguirre, L.; Arias, N.; Teresa Macarulla, M.; Gracia, A.; P. Portillo, M. Beneficial Effects of Quercetin on Obesity and Diabetes. The Open Nutraceuticals Journal 2011, 4.

37. Ding, Y.; Song, Z.; Li, H. Frontiers Honokiol Ameliorates High-Fat-Diet-Induced Obesity of Different Sexes of Mice by Modulating the Composition of the Gut Microbiota. Immunology 2019, 10, 2800, https://doi.org/10.3389/fimmu.2019.02800.

38. Bradford, P, G.; Curcumin and Obesity - Bradford - BioFactors 2013, 39, 1, 78-87, https://doi.org/10.1002/biof.1074.

39. Leung, F.W. Capsaicin as an Anti-Obesity Drug. In Capsaicin as a Therapeutic Molecule; Abdel-Salam, O.M.E., Ed. Progress in Drug Research. Springer: Basel 2014, 171-179, ISBN 978-3-0348-0828-6.

40. Harpaz, E.; Tamir, S.; Weinstein, A.; Weinstein, Y. The Effect of Caffeine on Energy Balance. Journal of Basic and Clinical Physiology and Pharmacology 2017, 28, 1-10, https://doi.org/10.1515/jbcpp-20160090 .

41. Firouzi, S.; Malekahmadi, M.; Ghayour-Mobarhan, M.; Ferns, G.; Rahimi, H.R. Barberry in the Treatment of Obesity and Metabolic Syndrome: Possible Mechanisms of Action. Diabetes Metab Syndr Obes 2018, 11, 699-705, https://doi.org/10.2147/DMSO.S181572.

42. Andraws, R.; Chawla, P.; Brown, D.L. Cardiovascular Effects of Ephedra Alkaloids: A Comprehensive Review. Progress in Cardiovascular Diseases 2005, 47, 217-225, https://doi.org/10.1016/j.pcad.2004.07.006.

43. Cheah, E.S. EDITORIAL Orlistat (Xenical) in the Management of Obesity.

44. Menendez, J.A.; Vellon, L.; Lupu, R. Antitumoral Actions of the Anti-Obesity Drug Orlistat (Xenical ${ }^{\mathrm{TM}}$ ) in Breast Cancer Cells: Blockade of Cell Cycle Progression, Promotion of Apoptotic Cell Death and PEA3Mediated Transcriptional Repression of Her2/Neu (ErbB-2) Oncogene. Annals of Oncology 2005, 16, 1253-1267, https://doi.org/10.1093/annonc/mdi239.

45. Carter, R.; Mouralidarane, A.; Ray, S.; Soeda, J.; Oben, J. Recent Advancements in Drug Treatment of Obesity. Clin Med (Lond) 2012, 12, 456-460, https://doi.org/10.7861/clinmedicine.12-5-456.

46. Torgerson, J.S.; Hauptman, J.; Boldrin, M.N.; Sjöström, L. XENical in the Prevention of Diabetes in Obese Subjects (XENDOS) Study. A Randomized Study of Orlistat as an Adjunct to Lifestyle Changes for the Prevention of Type 2 Diabetes in Obese Patients. Clinical Diabetology 2004, 5, 95-104.

47. Norinder, U.; Bergström, C.A.S. Prediction of ADMET Properties. ChemMedChem 2006, 1, 920-937, https://doi.org/10.1002/cmdc.200600155.

48. Larik, F.A.; Faisal, M.; Saeed, A.; Channar, P.A.; Korabecny, J.; Jabeen, F.; Mahar, I.A.; Kazi, M.A.; Abbas, Q.; Murtaza, G.; et al. Investigation on the Effect of Alkyl Chain Linked Mono-Thioureas as Jack Bean Urease Inhibitors, SAR, Pharmacokinetics ADMET Parameters and Molecular Docking Studies. Bioorganic Chemistry 2019, 86, 473-481, https://doi.org/10.1016/j.bioorg.2019.02.011.

49. Ekowati, J.; Diyah, N. W.; Nofianti, K. A.; et al. Molecular Docking of Ferulic Acid Derivatives on P2Y12 Receptor and Their ADMET Prediction. Journal of Mathematical and Fundamental Sciences 2018, 50, 2, 203-219, https://doi.org/10.5614/j.math.fund.sci.2018.50.2.8.

50. Abdelrheem, D.A.; Rahman, A.A.; Elsayed, K.N.M.; Abd El-Mageed, H.R.; Mohamed, H.S.; Ahmed, S.A. Isolation, Characterization, in Vitro Anticancer Activity, Dft Calculations, Molecular Docking, Bioactivity Score, Drug-Likeness and Admet Studies of Eight Phytoconstituents from Brown Alga Sargassum Platycarpum. Journal of Molecular Structure 2021, 1225, 129245, https://doi.org/10.1016/j.molstruc.2020.129245.

51. Erbing, Y.; Zhengming, L. The Lipinski's Rules in Drug Discovery. CHEMISTRY-PEKING 2006, 69, 1, 16. 